\title{
rTgOWP1-f, a specific biomarker for Toxoplasma gondii oocysts
}

\author{
Susana Sousa ${ }^{1,2,4 凶}$, André Almeida ${ }^{2}$, Lurdes Delgado ${ }^{1}$, Antónia Conceição ${ }^{3}$, \\ Cláudia Marques $^{1,2}$, José Manuel Correia da Costa ${ }^{1,2}$ \& António Castro ${ }^{1,2}$
}

Toxoplasma gondii oocyst wall protein 1 (TgOWP1) integrates a family of seven proteins, consensually assumed as specific antigens of Toxoplasma gondii oocyst stage, located in the outer layer of the oocyst wall. Herein, we notice the expression of a recombinant antigen, rTgOWP1-f, derived from a fragment selected on basis of its structural homology with Plasmodium MSP1-19. Rabbit polyclonal antibodies anti-rTgOWP1-f evidence ability for specific identification of environmental $T$. gondii oocysts. We assume, rTgOWP1-f, as a possible biomarker of oocysts. In addition, we present findings supporting this vision, including the development of an immunodetection method for $T$. gondii oocysts identification.

Toxoplasma gondii infections are widely prevalent in humans and animals worldwide ${ }^{1}$. Humans become infected postnatally by ingesting tissue cysts from undercooked meat and consuming food or drink contaminated with oocysts $^{2-5}$. The relative importance of transmission via tissue cysts versus oocysts is unknown ${ }^{4}$. Consensually, literature admits that oocysts can remain viable for long periods in environment and, in addition, they are resistant to chemical and physical treatment currently applied in water plants, including chlorination and ozone treatment ${ }^{6,7}$. However, the detection of Toxoplasma oocysts in water is complex, and no standardized methods are available. Recently, Heather Fritz and Patricia Conrad, $2018^{8}$, proposed a strategy for oocyst identification based on antibodies against a selected group of TyRP's and TgOWP2 proteins (US 2018/0017557A1). Herein, we propose a different approach: an immunofluorescence assay based on rabbit polyclonal antibodies against a selected sequence, rTgOWP1-f. The choice of TgOWP1 as a possible biomarker for environmental oocysts was based on its location in the outer layer wall of both sporulated and unsporulated oocysts ${ }^{9,10}$. However, a technical constraint was clear; TgOWP1 sequence and primary structure is complex, and presents additional difficulties in the expression of a homologue recombinant antigen in E. coli, because its low solubility and low expression ${ }^{9}$. To overcome the situation, we have submitted TgOWP1 sequence at structural searches by ExPASy workstation in order to identify fragments that may constitute targets to host immunological response. Curiously, we have remarked that several sequences within TgOWP1 gene present structural homology with Plasmodium merozoite surface protein 1 C-terminal 19-kDa fragment (MSP1-19). This peptide is involved in the interaction of Plasmodium merozoites with red cells membranes, and it is highly immunogenic in malarial infections ${ }^{11,12}$. This finding was critical for our choice. We designed specific primers to amplify the portion of the gene coding the sequence referred as TgOWP1-f and presenting structural homology with MSP1-19. A recombinant homolog sequence was expressed in an E. coli vector and purified. Polyclonal antibodies against the recombinant protein, rTgOWP1-f, obtained after rabbit and mice immunization, evidence a clear-cut ability to identify T. gondii oocysts.

\section{Results}

Structural analysis of TgOWP1. TgOWP1 is a 499-amino acid protein, with a putative signal peptide sequence, followed by six type I (six-cysteine) domains and by a single four-cysteine type I domain at the C-terminus. Type II domains are absent in TgOWP1. The domain structure of TgOWP1 (Fig. 1a) was previously described ${ }^{13}$. Analysis of proteins containing sequences homologues to the TgOWPf with BLAST shows high identity values ( $>90 \%$ ) with proteins from T. gondii and with an oocyst wall protein of Hammondia hammondi (Fig. 1d). ExPASy workstation was utilized in the search for structural homologies, and highlighted the presence of two fragments with significant homology to the C-terminal sequence of Plasmodium merozoite surface protein I (MSP1-19) (Fig. 1c). The TgOWP1-f shows significant structural homology with P. yoelii MSP1-19 (sample 2mgp.1.A from ExPASy Structural database) ${ }^{14}$ with values of Global Model Quality Estimation (GMQE)

${ }^{1}$ Center for Parasite Biology and Immunology, National Institute of Health Dr Ricardo Jorge, Rua Alexandre Herculano 321, 4000-055, Porto, Portugal. ${ }^{2}$ Center for the Study of Animal Science (CECA)/Institute for Agricultural and Agro-Alimentary Science and Technology (ICETA), University of Porto, Porto, Portugal. ${ }^{3}$ Coimbra Polytechnic PT, Bencanta, 3045-601, Coimbra, Portugal. ' LAQV, REQUIMTE, Department of Chemistry and Biochemistry, Faculty of Sciences, University of Porto, Porto, Portugal. ${ }^{\bowtie}$ e-mail: adelaide.sousa@insa.min-saude.pt 
A)

MKLVFPAVCVVALSSETLLKLALGNPGVPPVP

\begin{tabular}{llll} 
& \multicolumn{3}{c}{ Fragment I } \\
$34-102$ & CPPGFSLEQRGCVRSRQVPPIMR & CAKKVLAGNECVTTEFAPSIEV & CPEGFIEKNRKCRRVVNAQPQLG \\
$103-172$ & CKPGFTLQNGGDCIRVTEDDIITR & CPPKSKHTSKGCVTVEKLDVVPS & CPRGYELKNACIMTQNIEPVPS \\
$173-241$ & CPQGFAFESGACVRTGAVPPRVS & CPRGYKRQDNGCVLFEKHDLEAF & CRDGEYDGKKHCRKTTTQPALPH \\
& \multicolumn{3}{c}{ Fragment II } \\
$242-310$ & CPAGFSFQNGECVRVQEDIARLE & CGKGFTLHEDRCVKEVTVAAELQ & CPPGATLMKDKCAILTSEKPAVT \\
$311-380$ & CPDKFIMADGVCKSADVRPAEFV & CPKGYTMDRGTGGCVRSTTAKPALS CERGELKKGECSMIQTVPAETA \\
$381-453$ & CILGGALTPDGCVFIDTAPLSHR & CGVNFKMDIKGQCATVETIDPEHI & CPPGFAPSGTKKATCERFLTSPAAIK \\
$454-499$ & CPAGFEPAGTKCMKTARIQAIAS & CPHGFVFHEGACIPYKANGKKKL &
\end{tabular}

B)

CPPGFSLEQRGCVRSRQVPPIMRCAKKSVLAGNECVTTEFAPS IEVCPEGF IEKNRKCRRVVNAQPQLGC ccttcccccccccccccchhhhhhheeettcceeeeect teeecttceehttcccheeeeccccccc KPGFTLQNGGDCIRVTEDDIITRCPPKSKHTSKGCVTVEKLDVVP

ctteeecttcceeeeccceeccttcccccceeeeeeeec

$\begin{array}{ccccc}\text { SOPMA : Alpha helix } & (\mathrm{Hh}): & 9 \text { is } & 9.09 \% \\ \text { Extended strand } & (\mathrm{Ee}): & 27 \text { is } 27.27 \% \\ \text { Beta turn } & (\mathrm{Tt}): & 11 \text { is } 11.11 \% \\ \text { Random coil } & \text { (CC) : } & 52 \text { is } 52.53 \%\end{array}$

C)

Mode1_04 CPPGISIEQRGCVRSROVPPIURCARRSVL-AGNBCVTTBPAPSIBVCPBG--PIBKNRR 57 2 mgp.1.A

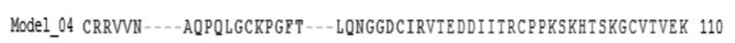

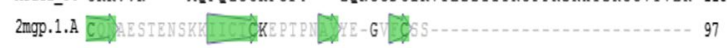

Mode__o4 LDVWPSCPRGYEuKKNACLMTQNiEPVPS

139

2 mgp. 1.A

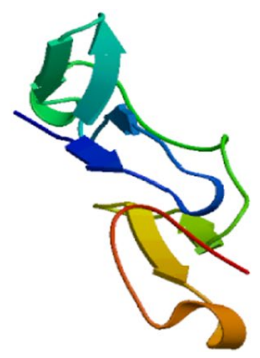

D)

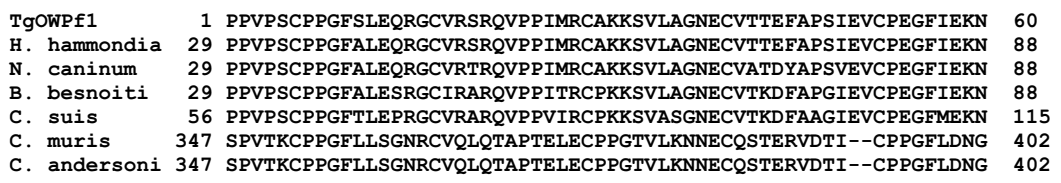

$\begin{array}{lrlll}\text { TgOWPf1 } & 61 & \text { RKCRRVVNAQPQLGCKPGFTLQNGGDCIRVTEDDIITRCPPKSKHTSKGCVTVEKLDVVP } & 120 \\ \text { H. hammondia } & 61 & \text { RKCRRVVNAQPQLGCKPGFTLQNGGDCIRVTEDDIITRCPPKSKHTSKGCVTVEKLDVVP } & 148 \\ \text { N. caninum } & 89 & \text { RKCRRVINAQPELGCKPGFTLNGGDCIRVVDDIITRCPPKKHTSKGCVTVEKLDAVP } & 148 \\ \text { B. besnoiti } & 89 & \text { RKCRKVINAQPELGCRPGFILQPGGDCIRVIEDEVITRCPPRSKQTSKGCVTVEKLDVIL } & 148 \\ \text { C. suis } & 116 & \text { RKCRKVISVQPELGCKKGFALQAGGDCVRAGEDDVITRCPKHSKQTSKGCITVQKVDVEY } & 173 \\ \text { C. muris } & 403 & \text { QDC--VQFAAPEKSCPPGFSL-SGKQCIQTETSPRNPLCPPGTTMEGNTCVAVELIDAVC } & 462 \\ \text { C. andersoni } & 403 & \text { QDC--VQFAAPEKSCPPGFSL-SGKQCIQTETSPRNPLCPPGTTMEGNTCVATELIDAVC } & 462\end{array}$

Figure 1. Analysis and description of rTgOWP1 fragment. A) Partial sequence of protein TgOWP1 and identification of the fragment TgOWP1-f; The amino-acid sequence corresponding to TgOWP1-f is identified with grey background; The sequences $34-102 ; 103-172 ; 173-241 ; 242-310 ; 311-380 ; 381-453 ; 454-499$ are the TgOWP1 cysteine-rich motifs. Sequences with structural homology with merozoite surface protein I are underscored and identified as Fragment I and Fragment II. B) Structural data TgOWP1-f; The TgOWP1-f (Fragment I) sequence was analyzed by the SOPMA secondary structure prediction method. C) Structural comparison between the sequences of Fragment I and sequences from Plasmodium Merozoite surface protein 1. Fragment I structural comparison with sample 2mgp.1.A from MSP1-19 of $P$. Yollie; 3D ribbon image of TgOWP1-f predicted structure. D) Sequence alignment of TgOWP1-f of T. gondii (EU 851867) with H. hammondia - Hammondia hammondi oocyst wall protein 1 (KL 544053) fragment, N. caninun - Neospora caninum putative oocyst wall protein (XP 003882327) fragment, B. besnoiti - Besnoitia besnoiti oocyst wall protein (XP 029219539) fragment, C. suis - Cystoisospora suis oocyst wall protein (PHJ19967) fragment, C. muris - Cryptosporidium muris oocyst wall protein (XP 002140636) fragment, and C. andersoni Cryptosporidium andersoni oocyst wall protein (OII76225) fragment.

of 0.24 and Qualitative Model Energy Analysis (QMEAN) of - 3.53, and a sequence identity of 21.13\% (Fig. 1c). Structural analysis of the fragment TgOWP1, by Swiss Prot Modelling, and secondary structure tools ${ }^{15}$, suggest that the fragment has several extended strands separated by random coils (Fig. 1b). Here, we describe a truncated 
a)

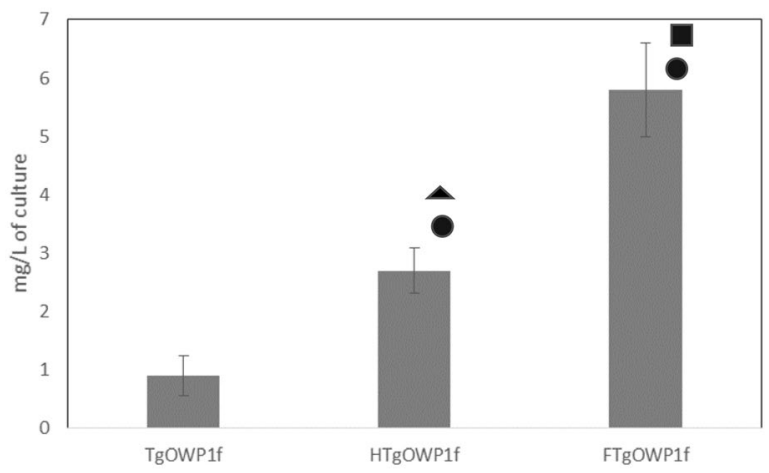

b)

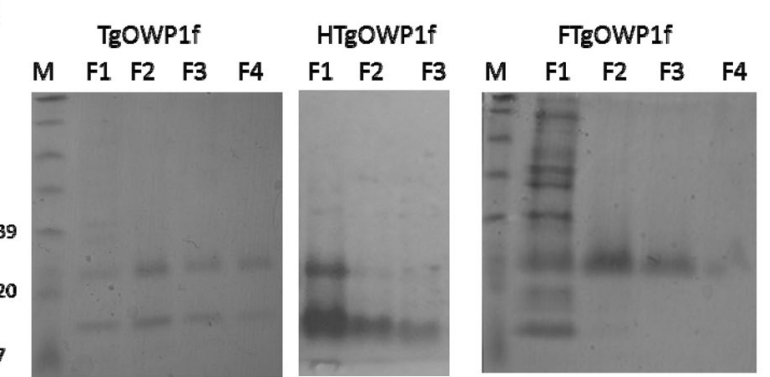

Figure 2. Expression of rTgOWP1-f into the vectors pQE30, pQE30H, and pQE30F. (a) Quantification of total protein for recombinant antigens rTgOWP1-f $(0.9 \mathrm{mg} / \mathrm{L})$, rHTgOWP1-f $(2.7 \mathrm{mg} / \mathrm{L})$, and $\mathrm{rFTgOWP} 1-\mathrm{f}$ $(5.8 \mathrm{mg} / \mathrm{L})$. Data represents means \pm standard deviation of triplicate experiments. Circle represents statistically significant difference from TgOWP1-f; triangle represents statistically significant difference from FTgOWP1-f; square represents statistically significant difference from HTgOWP1-f. (b) Analysis in Tris-tricine SDS-PAGE gel of the recombinant antigens rTgOWP1-f (15 kDa), rHTgOWP1-f (16kDa) and rFTgOWP1-f (23kDa). Four fractions were collected during proteins elution (F1, F2, F3, and F4).

protein of 120 amino acid (Fig. 1a in grey) corresponding to the second exon of the gene. The TgOWP1 fragment includes the first type I domain and the four-cysteine sequence of the second domain (Fig. 1a).

Expression and purification of TgWOP1-f recombinant antigens. TgOWP1-f was cloned into the vectors $\mathrm{pQE} 30$, and $\mathrm{pQE} 30 \mathrm{H}$ for immunological purposes ${ }^{13,16}$, and $\mathrm{pQE} 30 \mathrm{~F}^{13,17}$ for production purposes (Fig. 2a,b). As expected, antigens production showed a significant increase for both tags, although more important when the F-tag was used $(5.8 \mathrm{mg} / \mathrm{L}$ for rFTgOWP1-f, $0.9 \mathrm{mg} / \mathrm{L}$ for rTgOWP1-f and $2.7 \mathrm{mg} / \mathrm{L}$ for rHTgOWP1-f). Purified proteins were analyzed by SDS-PAGE (Fig. 2b). Molecular weight was slightly higher than expected (15 kDa for $\mathrm{rTgOWP} 1-\mathrm{f}, 16 \mathrm{kDa}$ for $\mathrm{rHTgOWP} 1-\mathrm{f}$ and $23 \mathrm{kDa}$ for $\mathrm{rFTgOWP} 1-\mathrm{f}$ ), probably associated to structural characteristic of TgOWP. rFTgOWP1-f antigen was used for serological assays to evaluate the presence of specific anti-TgOWP1-f antibodies.

Evaluation of TgOWP1-f immunogenicity. To confirm the development of antibodies against rTgOWP1-f, mice were immunized with soluble recombinant antigen without the use of adjuvant and ELISA evaluated their immunogenicity. The presence of specific antibodies against rTgOWP1-f was detected from the $3^{\text {rd }}$ week onwards (Fig. 3). A plateau was reached at day 35 after injection. Both antigens are immunogenic. However, the presence of the H-tag seems to increase the consistency of the level of antibodies against rTgOWP1-f. For production of specific antibodies against TgOWP1-f in rabbits, rHTgOWP1-f was used due to the increased levels of production.

Production of specific antibodies. In order to evaluate the specificity of the antibodies an immunoblotting assay was done using rTgOWP1-f under native (Fig. 4b) and denaturated conditions (Fig. 4a). Under native conditions, three bands with molecular weights compatibles with a monomer, a dimer and a trimer of rTgOWP1-f were observed, suggesting that rTgOWP1-f is able to form polymeric structures. Anti-rTgOWP1-f antibody recognized the native protein in oocysts (Fig. 5). However, does not recognized the protein in T. gondii tachyzoites.

Detection of T. gondii oocysts by immunofluorescence. Immunofluorescence assay was performed to evaluate the ability of antibodies anti-rHTgOWP1-f to detect oocysts previously treated with $\mathrm{NaOCl}$, as prior described $^{18}$. The immunofluorescence assays were done with oocysts in suspension and visualized without any fixation process. The immunoserum recognized the wall of both sporulated and unsporulated oocysts (SI - figure $\mathrm{B}$ and D). No significant fluorescence was observed with pre-immune and control negative serum (SI - figure E). In order to determine if the antibody is specific for oocysts, immunofluoresce assays were done with T. gondii 


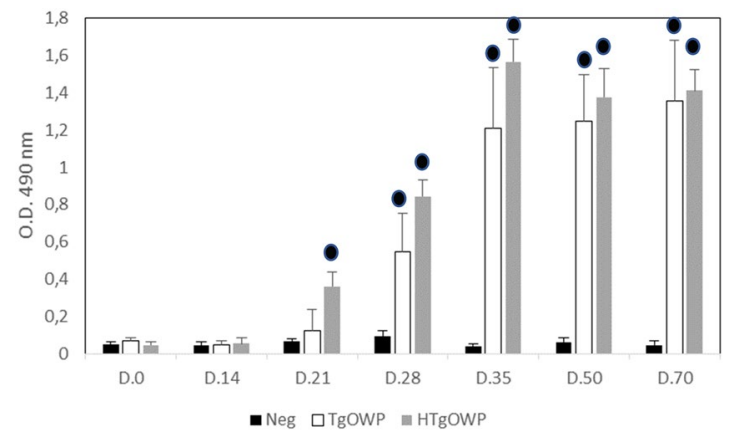

Figure 3. Analysis of specific anti-rTgOWP1-f IgG produced in mice upon immunization. Mice were injected IP either with $10 \mu \mathrm{g}$ of the respective recombinant antigen (rTgOWP1-f, rHTgOWP1-f) diluted in PBS or injected with PBS (control group). Sera was collected prior to injection (D.0) and the presence of IgG against TgOWP1 was detected by ELISA using rTgOWP1-f as antigen at day 14 (D.14), 21 (D.21), 28 (D.28), 35 (D.35), 50 (D.50), and 70 (D.70) after immunization. The optical density (OD) values were set on the mean absorbance reading for 3 mice \pm standard deviations. Circle represents statistically significant differences to controls.

tachyzoites. Antibodies anti-rHTgOWP1-f did not recognize T. gondii tachyzoites (SI - figure F). For detection of cross reactions, similar procedures were taken with Cryptosporidium parvum oocysts and Giardia lamblia cysts. No fluorescence was detected (SI - figure H).

\section{Discussion}

The detection of Toxoplasma oocysts remains an issue for many years. Herein we describe a new recombinant TgOWP1 derived-fragment, rTgOWP1-f, as biomarker for environmental oocysts. The TgOWP1 selection was based on i) its presence in the oocyst wall protein ${ }^{9}$, ii) not detectable in tachyzoites ${ }^{9}$, iii) neither in tissue cysts $^{10}$. Protein structure and function of TgOWPs family is not clear. Nevertheless, a potential role on the production of an extracellular matrix inducing heteropolymeric complexes stabilized by disulphide or di-tyrosine bridges has been suggested ${ }^{9}$. In addition, Santana et al., 2015 reported specific antibodies anti-TgOWP1 in naturally infected hosts $^{10}$, and Sotiriadou and Karanis, 2008, suggested it as target gene for the detection of T. gondii oocysts in natural water samples ${ }^{19}$. The selection of this specific TgOWP1 sequence/fragment was based on its structural homology with a C-terminal sequence of Plasmodium merozoite surface protein I-19 (MSP1-19) and, critically, high diversity comparing with TgOWP family proteins or in similar proteins from Cryptosporidium spp, Besnoiti spp, Hammondia hammondi and Neospora caninum. Our findings indicated high immunogenicity of rTgOWP1-f and a strong ability to recognize T. gondii oocysts specifically. Unfortunately, Neospora caninum or Hammondia hammondi oocysts were not available to be included in the assay. The sensitivity and specificity of these antibodies is critical for the development of ImmunoMagnetic Separation/IFA assay similar to EPA Method $1623^{20}$. So far, three monoclonal antibodies were described: $\mathrm{mAb} 3 \mathrm{G}^{21}$, $\mathrm{mAb} 4 \mathrm{B6}^{22}$, and MAb K8/15-15 ${ }^{23}$. Its specificity is under scrutiny. Recently, during a survey in order to detect and quantify the presence of T. gondii oocysts in fresh vegetables and fruits, usually raw eaten, the antibodies against rTgOWP1-f proved to be helpfully (Marques et al., ongoing work). Nevertheless, its specificity is under scrutiny, and deeper investigation are warranted in order to decipher the grade of environmental Toxoplasma oocysts contamination.

\section{Methods}

Study Approval. The maintenance and care of experimental animals complied with the Portuguese and European guidelines for the human use of laboratory animals. Mice were maintained in INSA animal facilities at the Centro de Saúde Pública Doutor Gonçalves Ferreira (CGF). The ethics committee for animal experimentation (ORBEA) from CGF approved all procedures. Mice were maintained in individual cages, and they received food and water ad libitum. Rabbits were maintained at Escola Superior Agrária de Coimbra (ESAC) animal facilities and the ethics committee (ORBEA) from ESAC approved all procedures. Rabbits were randomly allocated in separate stables.

Parasites. Oocysts of T. gondii ME49 strain (kindly provided by JP Dubey). Tachyzoites of T. gondii RH strain were obtained from intraperitoneal lavage from mice with $48 \mathrm{~h}$ of infection. Oocysts of Cryptosporidium parvum and cysts of Giardia lamblia from "Aqua-Glo G/C Direct Comprehensive Kit, Waterborne, Inc., New Orleans" were used as negative controls for immunofluorescence assays.

T. gondii oocysts lysate antigen. Approximatly $10^{7}$ oocysts were incubated overnight at room temperature with $1 \%$ Tween 80 . Oocysts were washed by centrifugation to remove Tween 80 , ressuspended in $200 \mu$ of SDS-PAGE sample buffer, boiled for 15 minutes and stored at $-20^{\circ} \mathrm{C}$ until use.

Preparation of T.gondii genomic DNA. Tachyzoites from the Toxoplasma gondii RH strain were washed three times in sterile saline solution and recovered by centrifugation at $1062 \mathrm{~g}$ for 10 minutes. Parasite suspension 
a)

\section{A0 B0 AI BI rTgU}

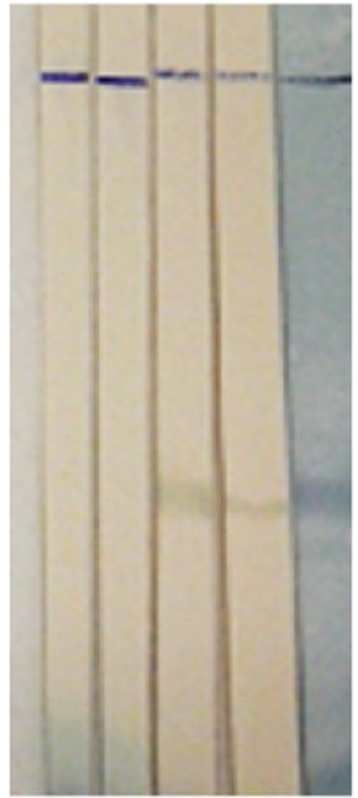

b)

\section{A0 B0 AI BI rTgND}

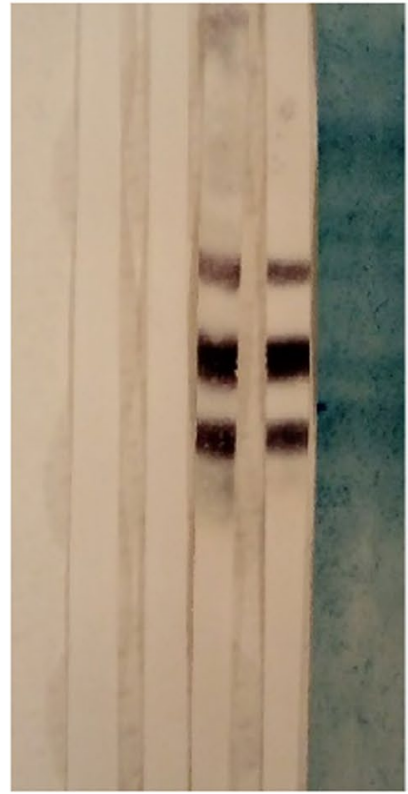

Figure 4. Immunoblotting with rTgOWP1-f. Rabbit sera raised against rHTgOWP1-f was evaluated using rTgOWP1-f in $8 \mathrm{M}$ Urea buffer (a) or rTgOWP1-f obtained in native conditions (b). A0, B0 - Sera from rabbit A or B collected before first immunization; AI, BI - Immunosera from rabbit A or B raised against rHTgOWP1-f.

was adjusted to $1 \times 10^{8}$ tachyzoites $/ \mathrm{ml}$ in sterile saline solution. The T. gondii genomic DNA was extracted with QIAamp DNA Mini Kit (Qiagen), according to the manufacturer's instructions.

Preparation of TgOWP1-f DNA. The amplification of a portion of TgOWP1 gene and the expression of a truncated protein was the strategy used to overcome the presence of several introns. The TgOWP1 


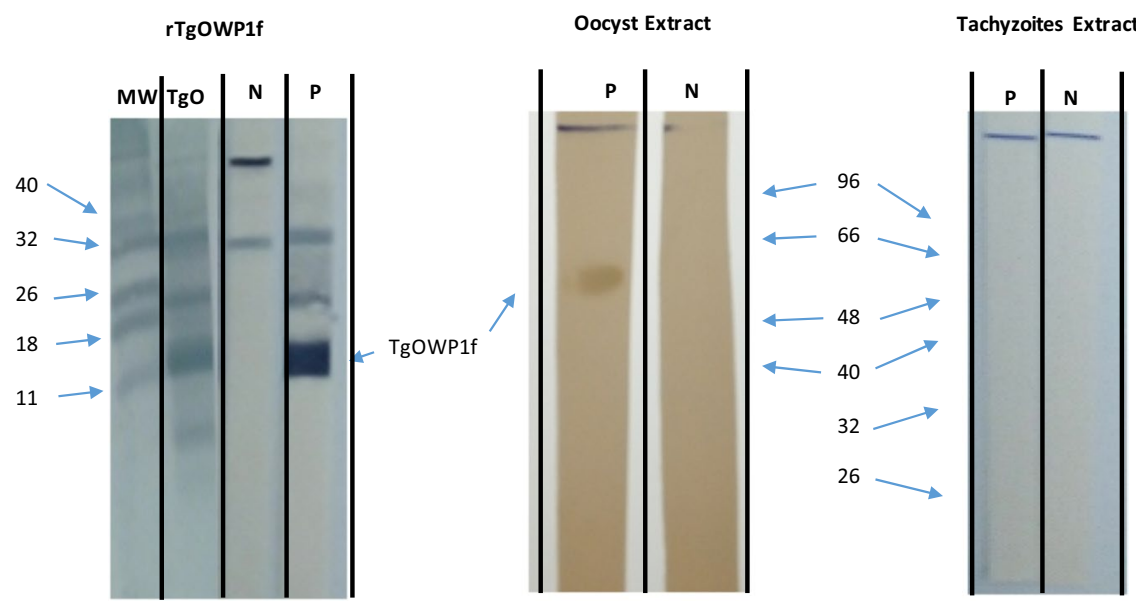

Figure 5. Identification of TgOWP1-f in T. gondii extracts. T. gondii oocyst and tachyzoites extract were probed with specific anti-TgOWP1-f sera $(\mathrm{P})$ or pre-immune $(\mathrm{N})$ sera to evaluate the presence of the antigen in the extract. MW - molecular weights; TgO - membrane with recombinant antigen $\mathrm{rTgOWP1-f}$ stained with Amido Schwartz; rTgOWP1-f - Immunobloting results using rTgOWP1-f antigen; Oocyst extract Immunobloting results using oocyst extract; Tachyzoites extract - Immunobloting results using Tachyzoites extract. rTgOWP1-f, oocysts extract and tachyzoite extract were not run on the same blotting and were not probed together with the anti-TgOWP1-f sera because we believe that specific antibodies could bind mainly to the recombinant antigen, hence decreasing the signal in the oocyst extract (competition effect).

gene possesses three introns of 206, 85 and 393 nucleotides length, and includes an amino-terminal intron that delineates a putative signal peptide sequence present on a short exon. Primers were designed in order to amplify the entirely second exon and introducing restriction enzyme recognition sites. Primers sequence were: TgOWP_SacI 5'-TGTGCCTGTGTGAGCTCCCTCCTGTG-3' and TgOWP_KpnI: 5'-TGATGCGCGGTACCCTAGGGAACGAC-3'. TgOWP fragment was amplified by PCR using $10 \mu \mathrm{lof}$ T. gondii DNA sample, $2 \mu \mathrm{l}$ of $25 \mathrm{mM} \mathrm{MgCl} 2,1 \mu \mathrm{l}$ of dNTPs mix $(1 \mathrm{mM}), 10$ pmol of each primer, $5 \mu \mathrm{l}$ of Taq buffer (Thermo Scientific), and ultra-pure water to complete a $50 \mu$ l volume. PCR amplification was performed with an initial denaturation step $\left(4 \mathrm{~min}\right.$ at $\left.95^{\circ} \mathrm{C}\right)$, followed by 30 cycles of denaturation $\left(30 \mathrm{~s}\right.$ at $\left.95^{\circ} \mathrm{C}\right)$, annealing $(30 \mathrm{~s}$ at $50^{\circ} \mathrm{C}$ ), and extension $\left(1 \mathrm{~min}\right.$ at $72^{\circ} \mathrm{C}$ ). The program included a final extension step of $7 \mathrm{~min}$ at $72^{\circ} \mathrm{C}$, and it was performed in a C1000 Touch Thermal Cycler (Bio-Rad). PCR fragment was separated in LMAg and isolated with illustra GFX PCR DNA \& Gel Band Purification Kit (GE Healthcare) according to the manufacturer's instructions.

Subcloning of TgOWP1-f. The TgOWP1 fragment was subcloned in pGEMT easy vector (Promega) and transformed into E. coli XL1 Blue cells. The pGEMT - TgOWP plasmid was isolated with Wizard Plus SV Miniprep DNA Purification System Kit (Promega) and sequenced at Eurofins (Germany) sequencing services. The fragment was isolated from pGEM-TgOWP plasmid upon digestion with SacI (Promega) and KpnI (Promega) restriction enzymes and subcloned in the vector pQE30 (Qiagen), the vector pQE30 with the H-tag, and the vector pQE30 with the F-tag ${ }^{13,16,17}$.

Expression and purification of TgOWP1 proteins in E. coli. E. coli were cultivated in LB medium supplemented with ampicillin $(100 \mu \mathrm{g} / \mathrm{ml})$ and kanamycin $(50 \mu \mathrm{g} / \mathrm{ml})$ at $37^{\circ} \mathrm{C}$. The culture was induced with $1 \mathrm{mM}$ of isopropyl- $\beta$-D-1-thiogalactopyranoside (IPTG) for $5 \mathrm{~h}$ at $37^{\circ} \mathrm{C}^{17}$. Cells were harvested by centrifugation at $4000 \mathrm{~g}$ during 15 minutes at $4^{\circ} \mathrm{C}$, and the pellet was lysed with $8 \mathrm{M}$ urea, $\mathrm{pH} 8.0$, overnight at room temperature and constant stirring of $150 \mathrm{rpm}$. Cell extracts were centrifuged at $10.000 \mathrm{~g}$ for 20 minutes and resulting supernatant and pellet were collected separately for further analyses. The supernatant was applied into a Ni-NTA column (Qiagen) pre-equilibrated with $8 \mathrm{M}$ urea, $\mathrm{pH}$ 8.0. Ni-NTA purification was conducted according to the manufacturer's instructions ${ }^{24}$, and the protein elution performed by a $\mathrm{pH}$ decrease from 8.0 to 4.5 . SDS-PAGE gels stained with Coomassie-blue dye was used to analyze the purity of collected fractions from Ni-NTA chromatography. Protein concentration of each collected fraction was determined by Bradford assay.

Immunization of mice. In order to remove endotoxins, rTgOWP1-f and rHTgOWP1-f were treated with Polymixin B beads (Pierce) according to manufacturer's protocol. Finally, filtered through a $0.22 \mu \mathrm{m}$ filter (Millipore) and stored at $-20^{\circ} \mathrm{C}$ until use. Quantification of protein was performed according to the Bradford Method (Bio-Rad). Immunization of BALB/c mice (10 to 12 weeks old) after inoculation with $10 \mu \mathrm{g}$ of recombinant antigen in a $200 \mu \mathrm{l}$ final volume (in apirogenic PBS), via intraperitoneal, during 35 days (five boosts at days $0,14,21,28$, and 35). A group including three mice was performed for each of both recombinant antigens. The experiment includes a control group inoculated with PBS. Blood samples collected in tail vein were taken prior to immunization and at days $14,21,28,35,50$ and 70 , and preserved at $-20^{\circ} \mathrm{C}$. 
White rabbit immunization. The recombinant antigen $\mathrm{rTgOWP}-\mathrm{f}$ was dialyzed against phosphate buffer solution and concentrated using Centricon 3 (Millipore) to a final concentration of $1 \mathrm{mg} / \mathrm{ml}$, and sterilized using a $0.22 \mu \mathrm{m}$ filter (Millipore). Aliquots were stored at $-20^{\circ} \mathrm{C}$. A New Zealand white rabbit was immunized, subcutaneously, once a day, during two weeks, with $100 \mu \mathrm{g}$ of rTgOWP1-f in $500 \mu \mathrm{l}$ of inoculum, using Alum as adjuvant. A blood sample was collected from the ear, once a month, and preserved at $-20^{\circ} \mathrm{C}$.

Immunofluorescence. T. gondii ME49 oocysts concentrated at $1 \times 10^{4} / \mathrm{ml}$ were treated with bleach $(\mathrm{NaOCl})$ diluted in water to obtain final concentration ranging at $0.5,50$ and $500 \mathrm{mg}$ of NaOCl per liter during $20 \mathrm{~min}-$ utes at room temperature ${ }^{18}$. A solution of $10 \%$ sodium thiosulfate was added to neutralize any residual $\mathrm{NaOCl}$. Oocysts were recovered by centrifugation for 10 minutes at $1000 \mathrm{~g}$, ressuspended in $1 \mathrm{ml}$ of $1 \%$ Tween 80 and washed three times in PBS - Tween 20 0,3\% (PBST) for 10 minutes at $1000 \mathrm{~g}$. Oocysts were ressuspended in diluted (1:40) rTgOWP1-f-immunized sera or negative serum and incubated at $37^{\circ} \mathrm{C}$ for $1 \mathrm{~h} 30 \mathrm{~m}$. Samples were washed twice in PBS, ressuspended in PBST containing anti-rabbit Ig-FITC diluted at 1:100, and incubated at $37^{\circ} \mathrm{C}$ for $1 \mathrm{~h}$. Oocysts were visualized in a Nikon fluorescence microscope (Nikon EFD-3). Images with 400-x magnification were done using a PowerShot A630 digital camera (Canon).

Enzyme-linked immunosorbent assay. The ELISA tests were performed using 96-well Nunc (Roskilde, Denmark) plates coated with $10 \mu \mathrm{g} / \mathrm{ml} \mathrm{rTgOWP1-f} \mathrm{in} 0.1 \mathrm{M}$ carbonate/bicarbonate buffer, $\mathrm{pH} 9.6$, by incubation overnight at $4{ }^{\circ} \mathrm{C}$ in a moist atmosphere. The plates were washed twice in PBS-T. The remaining binding sites were blocked with $0.3 \%(\mathrm{w} / \mathrm{v})$ gelatin in PBS-T for 1 hour at $37^{\circ} \mathrm{C}$. The sera of BALB/c mice were diluted to 1:500 in PBS-T and incubated for 2 hours at $37^{\circ} \mathrm{C}$. The wells were washed three times with PBS-T. Protein A horseradish peroxidase conjugate (Bio-Rad) was diluted at 1:2000 in PBS-T and incubated for $2 \mathrm{~h}$ at $37^{\circ} \mathrm{C}$. The wells were washed three times with PBS-T and developed with o-phenylenediamine (OPD) for 15 minutes at $37^{\circ} \mathrm{C}$. Reaction was stopped with $\mathrm{HCl} 3 \mathrm{M}$ and absorbance was measured at $490 \mathrm{~nm}$.

Western blot. SDS-PAGE was carried out using SE 250 Mini-Vertical unit (GE Biosciences). Tris-tricine gel $^{25}$ was loaded with $100 \mu \mathrm{g}$ of rTgOWP1-f or $1 \mathrm{mg}$ of $T$. gondii tachyzoites extract (single well comb). Oocysts lysate antigen $\left(\sim 2 \times 10^{6}\right.$ oocysts) was loaded in a single well (10-well). After electrophoresis in $15 \%$ SDS-PAGE Tris-tricine gel and transferred to nitrocellulose membranes using a sandwich system using a T22 mini tank transfer unit (GE Biosciences). For rTgOWP1-f and T. gondii tachyzoites antigens a strip containing the protein marker and part of the antigen was cut from both nitrocellulose membranes and stained with Amido Schwartz reagent. The rest of the membranes were saturated with 5\% PBS-milk solution for $1 \mathrm{~h}$ at room temperature. In the case of T. gondii oocysts antigens each single lane was cut and saturated (lane containing molecular weights was attained with Amido Schwatz). Membrane strips were incubated with rabbit anti-rHTgOWP1-f, mice anti-rTgOWP1-f, or pre-immune sera overnight at $4{ }^{\circ} \mathrm{C}$. Protein G-peroxidase and anti-mouse IgG $(\mathrm{H}+\mathrm{L})-\mathrm{HRP}$ (Bio-Rad) were used as conjugate for rabbit and mice sera respectively, and 4-chloro-1-naphthol in cold methanol, PBS and hydrogen peroxide for protein detection ${ }^{17}$.

Data analysis. Data analysis was performed using the statistical analysis software SPSS v. 15.0 (SPSS Inc). Differences between arithmetic means were evaluated by Student's $t$-test. Differences with a confidence interval of $95 \%$ or higher were considered statistically significant $(P \leq 0.05)$.

\section{Data availability}

The datasets used and analysed in the current study are available from the corresponding author in response to reasonable requests.

Received: 11 November 2019; Accepted: 16 April 2020;

Published online: 14 May 2020

\section{References}

1. Dubey, J.P. \& Beattie, C. P. Toxoplasmosis of animals and man. (CRC press, Inc., 1988)

2. Dumètre, A. \& Dardé, M. L. How to detect Toxoplasma gondii oocysts in environmental samples? FEMS Microbiol Rev. 27, 651-661 (2003).

3. Dubey, J. P. et al. Prevalence of viable Toxoplasma gondii in beef, chickens, and pork from retail meat stores in the United States: Risk assessment to consumers. J Parasitol. 91, 1082-1093 (2005).

4. Robert-Gangneux, F. \& Marie-Laure Dardé, M. L. Epidemiology of and diagnostic strategies for toxoplasmosis. Clin Microbiol Rev. 25, 264-296 (2012).

5. Shapiro, K. et al. Simultaneous detection of four protozoan parasites on leafy greens using a novel multiplex PCR assay. Food Microbiol. 84, 103252 (2019).

6. Dumètre, A. et al. Effects of ozone and ultraviolet radiation treatments on the infectivity of Toxoplasma gondii oocysts. Vet. Parasitol. 153, 209-213 (2008).

7. Freppel, W. et al. Structure, composition, and roles of the Toxoplasma gondii oocyst and sporocyst walls. Cell Surf. 5, e100016 (2019).

8. Fritz, H., \& Conrad, P. Antibodies to the surface of Toxoplasma gondii oocysts and methods of use thereof. United States Patent Application Publication. Pub. No.: US 2018/0017557 A1. Available at, https://patentimages.storage.googleapis.com/f7/ b2/64/6f24a00e2779a9/US20180017557A1.pdf (2018).

9. Possenti, A. et al. Molecular characterization of a novel family of cysteine-rich proteins of Toxoplasma gondii and ultrastructural evidence of oocyst wall localization. Int J Parasitol. 40, 1639-1649 (2010).

10. Santana, S. S. et al. CCp5A protein from Toxoplasma gondii as a serological marker of oocyst-driven infections in humans and domestic animals. Front Microbiol. 6, 1305 (2015).

11. Wilson, D. W. et al. Quantifying the importance of MSP1-19 as a target of growth-inhibitory and protective antibodies against Plasmodium falciparum in humans. PLoS One. 6, e27705 (2011). 
12. Priest, J. W. et al. Specificicy of the IgG antibody response to Plasmodium falciparum, Plasmodium vivax, Plasmodium malariae, and Plasmodium ovale MSP119 subunit proteins in multiplexed serologic assays. Malar J. 17, 417 (2018).

13. Costa, S. J. et al. The Fh8 tag: A fusion partner for simple and cost-effective protein purification in Escherichia coli. Protein Expr Purif. 92, 163-170 (2013).

14. Artimo, P. et al. ExPASy: SIB bioinformatics resource portal. Nucleic Acids Res. 40, W597-W603 (2012).

15. Combet, C., Blanchet, C., Geourjon, C. \& Deléage, G. NPS@: network protein sequence analysis. Trends Biochem Sci. 25, 147-150 (2000).

16. Costa, S. J., Almeida, A., Castro, A., Domingues, L. \& Besir, H. The novel Fh8 and H fusion partners for soluble protein expression in Escherichia coli: A comparison with the traditional gene fusion technology. Appl Microbiol Biotechnol. 97, 6779-6791 (2013).

17. Costa, S. J. et al. A novel adjuvant-free $\mathrm{H}$ fusion system for the production of recombinant immunogens in Escherichia coli: Its application to a $12 \mathrm{kDa}$ antigen from Cryptosporidium parvum. Bioengineered. 4, 413-419 (2013).

18. Freppel, W. et al. Macrophages facilitate the excystation and differentiation of Toxoplasma gondii sporozoites into tachyzoites following oocyst internalization. Sci Rep. 6, 33654 (2016).

19. Sotiriadou, I. \& Karanis, P. Evaluation of loop-mediated isothermal amplification for detection of Toxoplasma gondii in water samples and comparative findings by polymerase chain reaction and immunofluorescence test (IFT). Diagn Microbiol Infect Dis. 62, 357-365 (2008).

20. EPA. Method 1623.1: Cryptosporidium and Giardia in Water by Filtration/IMS/IFA. Available at, https://nepis.epa.gov/Exe/ZyPDF. cgi/P100J7G4.PDF?Dockey=P100J7G4.PDF (2012).

21. Dumètre, A. \& Dardé, M. L. Immunomagnetic separation of Toxoplasma gondii oocysts using a monoclonal antibody directed against the oocyst wall. J Microbiol Methods. 61, 209-217 (2005).

22. Dumètre, A. \& Dardé, M. L. Detection of Toxoplasma gondii in water by an immunomagnetic separation method targeting the sporocysts. Parasitol Res. 101, 989-996 (2007).

23. Gondim, L. F. et al. Characterization of an IgG monoclonal antibody targeted to both tissue cyst and sporocyst walls of Toxoplasma gondii. Exp Parasitol. 163, 46-56 (2016).

24. The QIAexpressionist. A handbook for high-level expression of 6xHis-tagged proteins. Fifth edition (QIAGEN, 2003).

25. Schagger, H. \& Jagow, G. Tricine-sodium dodecyl sulfate-polyacrylamide gel electrophoresis for the separation of proteins in the range from 1 to $100 \mathrm{kDa}$. Anal. Biochem. 166, 368-379 (1987).

\section{Acknowledgements}

The authors would like to thank JP Dubey for kindly providing the T. gondii ME49 oocysts used in this work and Pedro Silva for technical assistant. This research was supported by the Horizon 2020 project SafeConsume (Grant Agreement No. 727580), and FCT funding UIDB/00211/2020.

\section{Author contributions}

S.S., A.A. and António Castro participated in the design of the experiments. S.S. wrote the manuscript. A.A. produced the recombinant antigens. L.D. and Antónia Conceição were responsible for immunization experiments. António Castro carried out structural analysis. S.S. and C.M. carried out the immunofluorescence experiments. J.M.C.C. substantively revised the manuscript.

\section{Competing interests}

The authors declare no competing interests.

\section{Additional information}

Supplementary information is available for this paper at https://doi.org/10.1038/s41598-020-64590-4.

Correspondence and requests for materials should be addressed to S.S.

Reprints and permissions information is available at www.nature.com/reprints.

Publisher's note Springer Nature remains neutral with regard to jurisdictional claims in published maps and institutional affiliations.

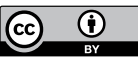

Open Access This article is licensed under a Creative Commons Attribution 4.0 International

License, which permits use, sharing, adaptation, distribution and reproduction in any medium or format, as long as you give appropriate credit to the original author(s) and the source, provide a link to the Creative Commons license, and indicate if changes were made. The images or other third party material in this article are included in the article's Creative Commons license, unless indicated otherwise in a credit line to the material. If material is not included in the article's Creative Commons license and your intended use is not permitted by statutory regulation or exceeds the permitted use, you will need to obtain permission directly from the copyright holder. To view a copy of this license, visit http://creativecommons.org/licenses/by/4.0/.

(C) The Author(s) 2020 